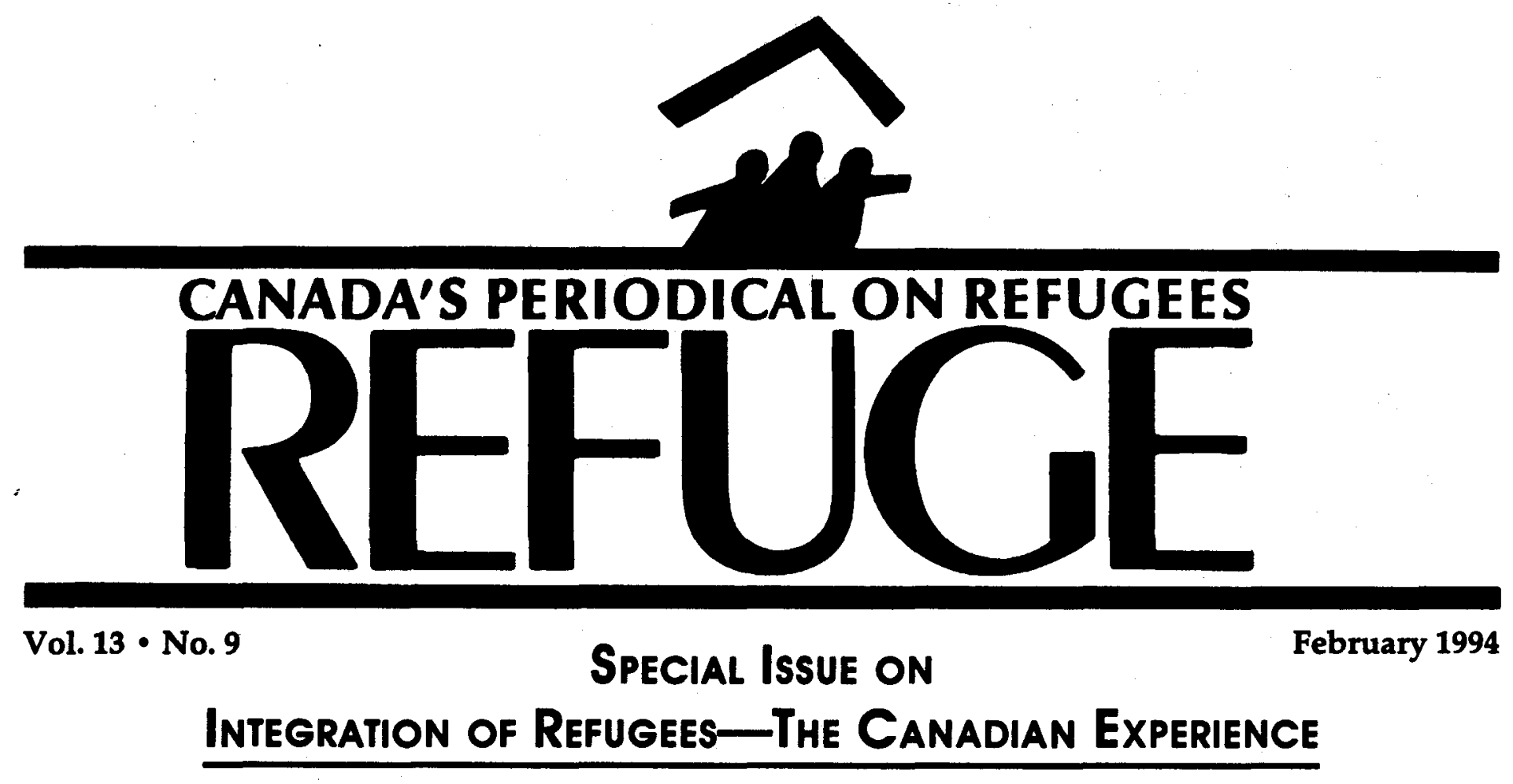

\title{
Today's Refugees-Tomorrow's Citizens
}

As a major recipient of refugees in the Western world since the 1970 s, Canada had to adapt to the task of enhancing the self sufficiency of the new arrivals and removing barriers from their full participation in social, cultural, economic and political activities. The main thrust of Canada's resettlement policy is "integration," generally defined as the process whereby immigrants and refugees become part of the social, institutional and cultural fabric of a society (Breton 1992).

Resettlement strategy is also influenced by the multicultural policy which permits the pluralistic existence of diverse cultures; newcomers are permitted or even encouraged to retain their prior internalized cultural values while gradually adjusting to life in Canada. As part of this process refugees will have to acquire mainstream Canadian values such as the ability to speak English/French and other social patterns. Also they may have to undergo occupational upgrading, retraining and other activities which are necessary for successful participation in Canadian society.
Canada's refugee resettlement strategy differs from that of assimilationist nations which require refugees to abandon prior internalized cultural values for their ultimate absorption into the culture of the receiving society. Whereas assimilationists dwell on totalistic change of values, integration recognizes cultural pluralism. Canada's refugee resettlement strategy rec- ognizes that integration goes beyond basic economic conditions such as income and employment, and encompasses other aspects including participation in social, cultural and political activities of Canadian society.

In their 1992 meeting on indicators of integration, the Canadian Academic Panel on the Social and Cultural Impacts of Immigration identified the following

\section{Contents:}

Today's Refugees-Tomorrow's Citizens Edward Opoku-Dapaah ... 1

Sowing New Foundations: Refugee and Immigrant Women and Support Groups Helene Moussa .................................................. 3

Latitud $45^{\circ}$ Nord: L'Exil au Canada Jaime LLambias-Wolff ................ 7 Integration of Landed Refugee Claimants in Canada:

Toward an Explanatory Model Edward Opoku-Dapaah ................... 10

The Traumas of Displacement David G. Hutton ................................. 16

The Multiculturalism Act and Refugee Integration in Canada

Fernando G. Mata

Predictors of Psychological Tension Among Refugees Living in

Montréal André Jacob, Joseph J. Lévy, Louis Robert Frigault

and Jocelyne Bertot

Service Delivery to Refugees and Immigrants:

Toward an Integrated Approach Perry Romberg. 


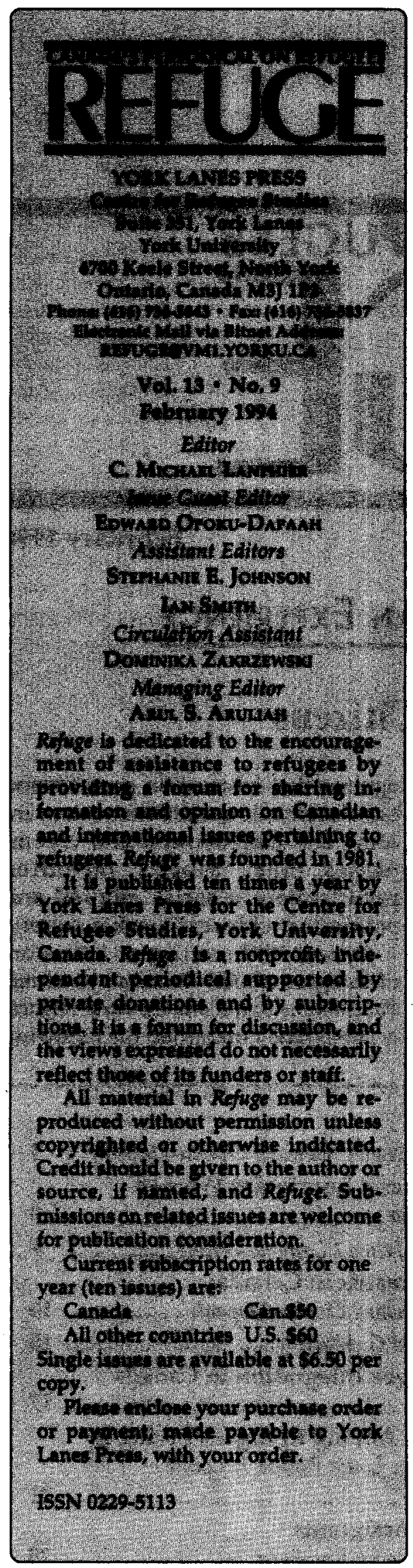

as essential components of the integration process (Breton 1992).

First, integration is a capacity and an end result. As a capacity, integration is the acquisition of the resources, information and other means necessary to function effectively in the new societal environment. As an end result, integration measures the degree of participation in the economic, political and general sociocultural life of the society.

Considered from the standpoint of the newcomers, the end result measures participation; and from the standpoint of the receiving society, outcomes relate to the contribution to the institutions, culture and demography of the society.

Second, integration is a two way process: the process of becoming part of a society engages those who are being incorporated as well as the entity that is incorporating them. Refugees who resettle in Canada must adjust to their new circumstances. Similarly, Canada's decision to accept refugees indicates a certain disposition to change in order to accommodate the newcomers.

Third, integration is not a one-time activity. Rather, it is a multidimensional process which can extend over several years of residence in the receiving Canadian society.

Finally, integration involves experiences that can vary across groups and social categories. Although the integration process has general parameters, the experiences of becoming part of the receiving society and the rate at which this occurs can differ from one individual to another, between refugees and regular immigrants and between inland refugee applicants and sponsored refugees.

Compared to other industrial nations such as the U.K. and the U.S., Canada's refugee integration strategy is deemed to be distinctive and also based on a sound ideological basis. Nonetheless, the ultimate test of the resettlement strategy is the ability to assist refugees in dealing with the challenges and opportunities associated with living in Canada.
A common theme running through the articles is the inadequacy of the settlement services to refugees. Helene Moussa's work, for example, challenges the ideology of mainstream service delivery and calls for a system tailored more specifically to the experiences and needs of refugee women and children. The principles of social justice, humanitarianism and cultural diversity that should form the basis of service delivery to refugees are frequently ignored; making refugees targets of media attacks and public embarrassment.

Jaime LLambias-Wolff's article outlines the integration experiences of refugees in Canada. In my article, I have attempted to present an explanatory model for the integration process of landed claimants. Fernando Mata's article outlines the administrative and legal foundations of Canada's multiculturalism policy in relation to refugee integration. This set the stage for an analytical assessment of what integration amounts to in practice. Jacob et al's study of Cambodian, Bulgarian, Guatemalan, Tamil and Ethiopian refugees in Montréal shows how the conditions of refugees can affect their psychological well being, and David Hutton provides valuable statistics on the traumas of displacement. Perry Romberg's article on the Jewish Immigrant Aid Services demonstrates how community based strategies can make a difference in the refugee resettlement process.

Together, this special issue depicts the institutional arrangements surrounding Canada's refugee resettlement strategy, first-hand experiences of refugees who have made Canada their new home, and the strategies that community agencies employ in the resettlement of refugees.

\section{Edward Opoku-Dapaah, Guest Editor}

\section{References}

Breton, Raymond. 1992. "Report on the Academic Advisory Panel on the Social and Cultural Impacts of Immigration." Strategic Planning and Research, Immigration Policy Group. Ottawa: Employment and Immigration Canada 